
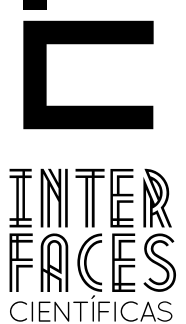

DIREITO

\title{
ENTRE AS LUVAS E AS GRADES: \\ CONSIDERAÇÕES SOBRE A EXPLORAÇÃO DOS NEGROS NA TEORIA DE LOÏC WACQUANT
}

Wagner Solano Arandas ${ }^{1}$

\section{RESUMO}

0 presente artigo se propõe a analisar, de forma preliminar, alguns estudos de Loïc Wacquant sobre o "não-lugar" do negro na sociedade norte-americana, em alguns momentos comparando com nosso paradigma. Através de uma breve análise de sua obra publicada no Brasil, este trabalho apoia-se na explanação acerca de duas linhas de pesquisa de Loïc Wacquant: (i) a exploração dos negros americanos no boxe e (ii) a segregação promovida pela política criminal. 0 objetivo central é ressaltar os aspectos de abordagem da sociologia jurídica sobre o racismo, traçando um paralelo entre o pugilista e o preso, envolvendo os pontos estruturais da exploração e do controle sobre estes indivíduos, que não por acaso compõe os estratos mais estigmatizados nas sociedades que os escravizaram no passado.

\section{PALAVRAS-CHAVE}

Sociologia Jurídica. Racismo. Política Criminal.

\section{ABSTRACT}

This article aims to analyze, in a preliminary way, some studies by Loïc Wacquant on the "no place" of blacks in American society, at times comparing it with our paradigm. Through a brief analysis of his works published in Brazil, this paper is based on an explanation about two research lines of Loïc Wacquant: (i) the exploitation of black Americans in boxing and (ii) segregation promoted by criminal policy. The main objective is to highlight aspects of the sociology of law on racism, drawing a parallel between the boxer and the prisoner, involving the structural points of exploitation and control over these individuals, who, not coincidentally, compose the most stigmatized strata in societies which had already enslaved them.

\section{KEYWORDS}

Sociology of Law. Racism. Crime Policy. 


\section{RESUMEN}

En este artículo se pretende analizar, de manera preliminar, algunos estudios de Loïc Wacquant, en el "no lugar" de los negros en la sociedad norteamericana, a veces comparando con nuestro paradigma. A través de un breve análisis de sus trabajos publicados en Brasil, este trabajo se basa en la explicación de dos líneas de investigación de Loïc Wacquant: i) la explotación de los negros estadounidenses en el boxeo y (ii) la segregación promovida por la política criminal. El objetivo principal es poner de relieve los aspectos de enfoque socio-jurídico sobre el racismo, trazando un paralelo entre el boxeador y el prisionero, con la participación de los puntos estructurales de la explotación y el control sobre estos individuos que, no por casualidad, componen los estratos estigmatizados en las sociedades que los esclavizaron en el pasado.

\section{PALABRAS CLAVE}

Sociología Jurídica. Racismo. Política de la Delincuencia.

\section{CONSIDERAÇ̃ES INICIAIS}

0 presente artigo se propõe a analisar, de forma preliminar, alguns estudos de Loïc Wacquant sobre o "não-lugar" do negro na sociedade norte-americana, em alguns momentos comparando com nosso paradigma. Nascido em uma pequena vila ao sul da França, Wacquant, iniciou seus estudos acadêmicos em Montpellier, Paris, onde pesquisou o controle francês nas ilhas do Pacífico. Porém, em agosto de 1988, quando realizava seus estudos de doutoramento em Chicago, um amigo the apresentou uma academia de boxe que se encontrava a algumas quadras do alojamento universitário, nas vizinhanças de Woodlawn, despertando em sua nata indagação de pesquisado a curiosidade em estudar os guetos americanos, assim o Woodlawn Boys Clubse tornou as cordas de seu universo de estudo.

Contudo, não apenas sentou-se em um canto do boxing gym e passou a anotar tudo que observava, ele começou a treinar com os boxers. E a partir deste trabalho passa a trazer contribuições de alta relevância para o estudo da estrutura de dominação, e para a pesquisa participante na etnografia, entrando de "corpo e alma" em seu objeto de estudo. Este evento influenciou muito sua obra, trazendo uma visão mais consistente da dominação, inclusive em seus estudos sobre as prisões.

Através de uma breve análise de sua obra publicada no Brasil, este trabalho apoia-se na explanação à cerca de duas linhas de pesquisa de Loïc Wacquant: (i) a exploração dos negros americanos no boxe e (ii) a segregação promovida pela política criminal. 0 objetivo central é ressaltar os aspectos de abordagem da sociologia jurídica sobre o racismo, traçando um paralelo entre o pugilista e o preso, envolvendo os pontos estruturais da exploração e do controle sobre estes indivíduos, que não por acaso compõe os estratos mais estigmatizados nas sociedades que os escravizaram no passado.

Estas reflexões a respeito da problemática do tema das prisões também se enquadram ao paradigma brasileiro. Todavia, não apresentando muita equivalência no boxe, pois, este esporte não representa no Brasil uma atividade altamente lucrativa, porém, existem estruturas próximas envolvendo o futebol, que por sinal, não perdoa os derrotados: "basta lembrar que a derrota do Brasil em 50, no campeonato mundial de futebol, provocou um recrudescimento do racismo", como bem nos lembra Mario Rodrigues Filho (2003, p. 16). 


\section{A EXPLORAÇ̃̃O DENTRO DO RINGUE}

Para ficar mais próximo do gueto e das pessoas exploradas pelo boxe, Wacquant treinou durante 35 meses em uma academia de boxe, observando este mundo em sua intimidade, adquirindo o habitus do boxeador. Esta vivência, go native, trouxe para sua pesquisa resultados dificilmente aferidos em uma simples observação. Os pugilistas criaram uma relação de confiança e cooperação, visto o fato destes informantes, muitas vezes, serem chamados de amigos por ele, compondo, desta forma, o corpus de sua pesquisa a partir de depoimentos sinceros, prestados com espontaneidade e sem ressalvas.

Um aspecto importante que possibilitou esta interação deriva-se do fato de Wacquant não ser um branco americano, condição que poderia inclusive inviabilizar seu trabalho. Pois, em geral no boxe os brancos americanos ocupam o papel de opressores, são eles os empresários e patrocinadores desta exploração, lucrando com o sacrifício dos negros e imigrantes.

Segundo Wacquant, a visão habitual dos críticos do boxe é equivocada em relação aos fatores que levam os indivíduos a adotarem este esporte como uma atividade profissional. Para os críticos, os boxers são marionetes sem consciência da exploração que sofrem. Contudo, o trabalho de pesquisa de campo de Wacquant verificou a falsidade desta hipótese.

O boxe difere pouco dos outros jogos sociais aos quais os jovens proletariados dos bairros pobres e decadentes têm acesso, uma vez que o sistema falido de escolas públicas só oferece oportunidades inviáveis e o mercado de trabalho não-qualificado, inchado com mão-de-obra barata, a longo prazo só acena com marginalidade (WACQUANT, 2000, p. 135)

O boxe é visto pelos jovens do gueto como um ofício, uma vocação, muitas vezes uma das poucas oportunidades de ganhar dinheiro honestamente. Eles têm noção da exploração que ronda este mercado de "carne e sangue”. Porém, ao mesmo tempo, estes acreditam que podem ser uma exceção, trabalhando o seu capital, representado pelo seu próprio corpo, o que é chamado de self-made man. Além de tudo, o boxe representa uma fuga dos problemas encontrados nas ruas.

Os negros veem a exploração no boxe como mais uma diante de várias que os circundam. No mercado de trabalho também há o patrão disposto a explorar a mão-de-obra barata dos trabalhadores desqualificados. No boxe, pelo menos, eles veem um caminho para trabalhar por conta própria, having a trade, apesar de em alguns casos não almejarem alcançar riquezas, mas sim a própria subsistência. Outros justificam que é explorado quem se deixa explorar.

Há uma ambiguidade envolvendo a exploração e a reconciliação. Apesar de representar um papel nocivo, os empresários são importantes para os boxeadores, que têm que se submeter ao status de mercadoria para conseguir lutas e patrocínios. São raras as denúncias de exploração, devido à má reputação no mundo do boxe, levando os profissionais a aceitarem se submeter a estas condições desfavoráveis.

Em condições de incerteza generalizada, em lugar de ficarem ressentidos com os empresários, alguns boxeadores se sentem gratos pela oportunidade que estes thes oferecem de fazer suas apostas nessa estranha loteria de corpos habilidosos que é o boxe (WACQUANT, 2000, p. 136).

Uma construção simbólica do vocabulário representa bem a relação de exploração através de metáforas, "a maioria dos lutadores, dependendo do seu talento, é vista pelos empresários como filé, outros como costelinhas de porco, e os menos talentosos como carne moída, mas é raro que sejam reconhecidos como seres humanos" (WACQUANT, 2000, p. 133), por isso, são chamados de mercadorias de carne e sangue.

No entanto, Loïc Wacquant chama a atenção para as metáforas que remetem a condições análogas a prosti- 
tuição, escravidão e a condição de animais. Na comparação com a prostituição, o lutador tem a exploração de seu corpo, submetido a intensos treinos. É oferecido nas ruas para lutar, enquanto o empresário, aqui visto como cafetão, fica do lado de fora do ringue colhendo os lucros. A comparação com a escravidão já traz em seu íntimo um forte simbolismo para os afro-americanos, nesta representação o ringue é a plantation e os boxers são os escravos, que lutam praticamente para sua subsistência, pois, o retorno econômico é infimamente menor que os lucros dos empresários, representados neste exemplo pelos senhores de escravos. Por fim, a comparação dos lutadores a animais, observação que restringe a condição humana, apresenta o indivíduo em um patamar de inferioridade, sem valores de seres humanos, sem respeito a direitos.

0 processo de reificação transforma os indivíduos em nada mais do que mercadorias, tudo pode ser passível de se tornar mercadoria no capitalismo, e no boxe não poderia ser diferente. O corpo é o capital do lutador como a força de trabalho é o capital do proletário, é o corpo que vai manter o boxeador na profissão. As boxing gym são verdadeiras linhas de montagem, onde o lutador é lapidado para gerar lucros para os exploradores desta atividade.

O gym é essa forja em que se modela o pugilista, a oficina em que se fabrica esse corpo-arma e armadura que ele se apressa por lançar em confronto no ringue, o cadinho em que são polidas as habilidades técnicas e os saberes estratégicos, cuja a delicada reunião faz o lutador acabado, enfim, o forno em que se alimenta a chama do desejo pugilístico e a crença coletiva no bom fundamento dos valores indígenas, sem os quais ninguém iria se arriscar de modo duradouro entre as cordas (WACQUANT, 2002, p. 32).

Técnicas de gerenciamento são empregadas pelos empresários, que exploram a cultura da virilidade, trabalhando o pugilista como um "gladiador moderno", visando ampliar a produção através da motivação da autoprodução corporal, do self-made man. Sendo este trabalhado como um dos principais requisitos para o crescimento no boxe. 0 outro seria a celebração de contratos, decorrentes do desempenho do lutador.

No boxe, os empresários muitas vezes ganham dos dois lados, ao colocar para lutar um boxerainda não preparado para enfrentar determinado adversário, ou sem o treinamento adequado, só para preparar o outro boxeador. Em alguns casos o empresário coloca seu lutador para perder mesmo, acordado entre os empresários a escalação de um pugilista sem chances de vencer. Desta forma, independente do resultado o empresário irá lucrar, “o boxe não passa de um 'negócio capitalista' como qualquer outro” (WACQUANT, 2000, p. 140).

Nem mesmo anos de dedicação ao boxe são garantias de uma melhoria de vida, quando o boxeador não possui mais condições de lutar, ele acaba perdendo o seu meio de subsistência. Como muitos não possuem outras qualificações, pois permaneceram muito tempo executando uma única atividade, não são considerados atrativos para o mercado de trabalho formal. Outros são tentados a partir para o ramo da ilegalidade.

Lembrando nosso paradigma, encontramos tais analogias no mundo do futebol, ou mesmo no âmbito social, como foi bem observado por Roger Bastide e Florestan Fernandes nos estudos do Projeto UNESCO, que identificaram que aos negros eram reservadas as características físicas, muitas vezes animalescas, assim como o desequilíbrio emocional. A trajetória do racismo em terras brasilis seguiu o rumo da cordialidade, sob uma frágil aparência de respeito entre brancos e negros. Contudo, Florestan Fernandes, Roger Bastide e Costa Pinto contribuíram de forma significativa para a desconstrução deste mito, "o habito da docilidade, de fazer exatamente o que o branco espera do negro, impede que se veja o lado moral do problema" (BASTIDE; FERNANDES, 2008, p. 192). A ausência de "confrontos" trouxe uma sensação de paz, apesar de esconder uma situação que embarreirava a mobilidade social. Esta "violência simbólica” submeteu os negros a uma situação complexa, pois sofriam as consequências do racismo, mas não possuíam "legitimidade" para lutar contra ele. 


\section{O CONTROLE DENTRO DA PRISÃO}

Um dado interessante questionado por Loïc Wacquant nos Estados Unidos é a congruência entre os períodos em que aumentam as taxas de desemprego, a polícia torna-se mais repressiva.

Utilizar a prisão como "aspirador social" para limpar as escórias das transformações econômicas em curso e retirar do espaço público o refugo da sociedade de mercado - os pequenos delinquentes ocasionais, os desempregados e os indigentes, os sem-teto e os sem documentos, os toxicômanos, os deficientes e doentes mentais deixados de lado por incúria da proteção sanitária e social, assim como os jovens de origem popular condenados a uma (sobre)vivência feita de expedientes e de furtos para suprir a precariedade dos salários - é uma aberração no sentido exato do termo (WACQUANT, 2004, p. 217).

Conforme Wacquant, a política penal é constituída para controlar as classes pobres e miseráveis, observando a população penitenciária de qualquer país, podemos observar quem se encontra preso, a exemplo do Brasil e Estados Unidos encontramos dentro das prisões os negros e pardos, pobres e trabalhadores desqualificados. 0 sistema penitenciário é a instituição que recebe a migração dos guetos, fruto da segregação racial.

Em síntese, e levando-se em conta a programação legal, deve-se concluir que o poder configurador ou positivo do sistema penal (o que cumpre a função de disciplinarismo verticalizante) é exercido à margem da legalidade, de forma arbitrariamente seletiva, porque a própria lei assim o planifica e porque o órgão legislativo deixa fora do discurso jurídico-penal amplíssimos âmbitos de controle social punitivo (ZAFFARONI, 2001, p. 25).

O código penal é um instrumento eficaz de controle, em geral, seus ordenamentos são destinados ao controle sobre as classes excluídas. Nas prisões se encontram mais acusados e condenados por furto e roubo do que criminosos do colarinho branco. Pois, esta segunda modalidade de crime em geral não é cometida por pessoas pobres, nem de baixa escolaridade. A política criminal é mais fácil de ser implementada do que a política social, prender um indivíduo não encaixado no sistema é bem mais prático do que investir em educação.

\begin{abstract}
0 encarceramento em grande escala induz um processo de mitridatização penal das populações que ele atinge regularmente, tornando-as pouco a pouco insensíveis à ação preventiva ou retributiva buscada pelas autoridades. Ao banalizar a repressão judiciária, o Estado esmaece o efeito que a cerca e apaga o estigma que lhe está associado, de tal modo que precisará sempre aumentar as "doses" de castigo necessárias para ajustar o comportamento dos que não se enquadram (WACQUANT, 2004, p. 222).
\end{abstract}

Há um perfil das pessoas que podem sofrer repressões mais duras da polícia, assim, como a sua submissão às práticas arbitrárias da política criminal. Estas pessoas carregam um estigma, que as tornam submissas a tais suplícios, banalizando o uso de determinadas práticas contra elas. Em geral, a sociedade não se choca quando a polícia bate em um suspeito na rua, exceto se ele possuir características peculiares a uma classe social mais privilegiada. Os pobres rotineiramente sofrem violências por parte da polícia, sem que esses abusos sejam combatidos. Uma teoria chamada labelling aproach trata da questão referente à tipificação penal de determinados delitos pautados no perfil dos indivíduos que os costumam cometer, como no caso do furto, comumente cometido por pobres, embora seja evidente que qualquer pessoa, independente da classe social, possa vir a cometer tal crime.

\begin{abstract}
Longe dos debates acadêmicos sobre as missões da prisão - reinserir, punir ou neutralizar -, a preocupação primordial dos responsáveis por estas verdadeiras fábricas de prender é pragmática e funcional: "fazer circular" o fluxo inexaurível de acusados e detentos o mais rápido possível através do "sistema" a fim de minimizar os incidentes ligados ao amontoamento e à mistura de populações díspares e difíceis, senão hostis (notadamente entre elas mesmas) (WACQUANT, 2003, p. 63-64).
\end{abstract}

Wacquant fala também sobre a "indústria do cárcere”, gerando empregos e lucros fáceis aos seus inves- 
tidores, pois, algumas federações americanas fomentam a criação de estabelecimentos privados. Gerando empregos diretos e indiretos. Entre os diretos, temos os próprios funcionários da prisão, e os indiretos representam as indústrias de armas, equipamentos de segurança, entre outros. 0 caráter hegemônico da economia de dominação precisa manter o equilíbrio sobre a pobreza e violência, para isso mantêm o seu controle através da prisão. No entanto, os excessos adotados pelo Estado muitas vezes se reverte através do aumento da violência.

O distanciamento dos serviços básicos como hospitais, escolas, mercado de trabalho, entre outros, configura mais uma modalidade de exclusão. A Inglaterra em suas colônias africanas "obrigou a mão-de-obra local a morar em barracos precários à margem de cidades segregadas e restritas" (DAVIS, 2006, p. 61). Muitos clubes também restringem o acesso a negros até hoje, quando só permitem a associação por indicação de membros antigos e a aceitação deste novo membro deve ser aceita pelos demais.

\begin{abstract}
Os contratos discriminatórios na compra e locação de imóveis (restrictive convenants) forçavam os afro-americanos a se amontoarem em um black belt que logo ficou superpovoado, subequipado e roído pelo crime, pela doença e pela deterioração, enquanto a discriminação no emprego (job ceiling) os encurralava nas profissões subalternas mais perigosas, degradantes e mal pagas, tanto na industria quanto nos serviços pessoais (WACQUANT, 2003, p. 113).
\end{abstract}

0 processo de urbanização brasileiro foi um movimento que não vislumbrava a integração do negro, as indústrias priorizavam a contratação dos imigrantes europeus, restando aos negros, na maioria das vezes, trabalhos precários. No caso das mulheres "o serviço doméstico, no qual as mulheres de cor constituem a maioria" (PINTO, 1998, p. 76) sempre foi um dos mais mal remunerados, assim como os demais postos de trabalhos ofertados às mulheres, que geram disparidades da média salarial entre homens e mulheres até hoje. Conforme a análise do biênio 2004-05 do Diee- se, em Salvador uma mulher negra recebia em média $39,2 \%$ do salário de um homem não-negro ${ }^{1}$.

A cor só entra em jogo, como marca racial, na medida em que ela também funciona como símbolo de status social. Dispomos de duas vias para descobrir essa forma dissimulada de preconceito e de discriminação raciais. De um lado, a que se oferece quando as convenções que regulam a acomodação racial são rompidas, unilateralmente, na polaridade "inferior". Ou seja, quando o negro ou o mulato se negam "a ser tratados como pretos" (mesmo nas condições de "preto de alma branca") [...] De outro lado, a que se descortina quando os "brancos" são forçados a exibir "o que se passa por dentro". Um pequeno incidente no tráfego, uma provocação ingênua dos melindres do entrevistado ou uma rixa podem contribuir poderosamente para "soltar a língua" (FERNANDES, 2008, p. 438).

Os espaços de maior prestígio da sociedade não são vistos pelos racistas como lugar para os negros, neste ponto semelhante aos outsiders apresentados por Norbert Elias, "a exclusão e a estigmatização dos outsiders pelo grupo estabelecido eram armas poderosas para que este último preservasse sua identidade e afirmasse sua superioridade, mantendo os outros firmemente em seu lugar" (ELIAS; SCOTSON, 2000, p. 22).

Um exemplo desse pensamento encontra-se na obra de Raymundo Nina Rodrigues (1862-1906). Médico, formado pela Faculdade de Medicina da Bahia, Nina Rodrigues dedicou-se ao estudo das culturas afro-brasileiras. Para ele, a razão do atraso e dos desequilíbrios da sociedade brasileira encontrava-se nas misturas raciais e culturais aqui existentes. Ao Contrário do que teria ocorrido nos Estados Unidos, onde a "direção suprema da Raça Branca" foi uma garantia de civilização, nossa inferioridade persistiria por um longo tempo. Para ele, a raça negra no Brasil seria sempre "um dos fatos da nossa inferioridade" e a intensidade da mestiçagem existente no país [...] Desse modo, ele deixava claro que o fator biológico era o principal responsável pela nossa inferioridade (BRYM; et al, 2006, p. 216).

Assim, interpreta-se que o racismo está para além das relações de poder, seja econômico, político ou de

$\overline{1 \mathrm{http}: / / w w w . d i e e s e . o r g . b r / e s p / e s t p e s q 14112005 \_m u l h e r n e g r a . p d f ~}$ 
qualquer natureza. 0 preconceito está no “reconhecimento do outro" e na "delimitação de espaços". O pensamento racista trabalha a representação dos negros como indivíduos inferiores. Teorias do "Racismo Científico" acreditavam que os Europeus do leste eram os seres humanos mais desenvolvidos na escala das espécies, "uma hierarquia das raças tomando por base capacidades intelectuais, físicas e até beleza" (BRYM; et al, 2006, p. 214). Mesmo "modelo" tomado como ideal em nossa sociedade, basta observar o biótipo das moças e rapazes presentes nas campanhas publicitárias, nas novelas, e em diversas mídias que representam a sociedade de consumo, que faz mais que vender um produto, essa indústria vende o nosso colonialismo. Pois, embora o povo brasileiro fale orgulhoso que tem um pouco de sangue das três "raças", quando se busca uma dupla nacionalidade, o segundo passaporte é europeu.

Desta forma, o ciclo sempre fecha sobre os mesmo indivíduos, “o inimigo é uma construção tendencialmente estrutural do discurso legitimador do poder punitivo" (ZAFFARONI; LEMGRUBER, 2007, p. 83). Não sendo estabelecido de forma oficial, porém, representado silenciosamente pelas práticas oficiosas, como um indivíduo que pratica grandes fraudes finan- ceiras, possui mais recursos para se esquivar. Assim como são as práticas de crimes mais vigiados, acaba constituindo uma observação maior sobre determinados crimes/indivíduos.

O sistema penitenciário brasileiro é o mais cruel paradigma de desrespeito à dignidade humana, assim como evidencia a seletividade de indivíduos, pois sua população se apresenta homogênea, em sua maioria, negros e pobres. As condições precárias das unidades prisionais agregam a pena restritiva de liberdade um suplício dantesco, “quando um juiz condena alguém ao cumprimento de uma pena de vinte anos, desconhece o magistrado se o apenado irá cumprir realmente esta pena" (BATISTA, 2005, p. 226). Já que, entre outros motivos diante da situação insalubre, o apenado morre antes de alcançar a liberdade, este é um dos prováveis fins do preso pobre.

Esta seletividade leva a algumas inquietações, que conduziram a constituição de uma corrente da criminologia a pensar de uma forma diferente a perspectiva do estudo do crime. Através da criminologia crítica, os estudos passam a analisar, entre outros objetos, a relação entre o crime e o etiquetamento dos indivíduos.

\section{CONSIDERACC̃̃ES FINAIS}

A censura legal sobre o autor tende a gerar consequências negativas ao Estado Democrático de Direito, estigmatizando determinadas classes e favorecendo outras. Conforme a criminologia crítica, o Direito Penal age como um instrumento de controle social sobre as classes menos favorecidas, a notoriedade deste fato se confirma com a observação da população carcerária, onde os pobres representam quase sua totalidade.

A luta dos direitos humanos nos Estados democráticos de direito, representam a dignidade humana como princípio fundamental deste modelo político, além de constituir "um veiculo indispensável de expressão da indignação que sentimos diante do sofrimento infringido aos nossos semelhantes" (RABENHORST, 2005, p. 115).

Desta forma, a seletividade representa um autoritarismo penal, e não o princípio iluminista do Direito moderno, remetendo a prática do Direito a períodos mais dogmáticos e menos doutrinários. 


\section{REFERÊNCIAS}

BASTIDE, Roger.; FERNANDES, Florestan. Brancos e negros em São Paulo. 4.ed. São Paulo: Global, 2008.

BRYM, Robert J. Sociologia: sua bússola para um novo mundo. São Paulo: Thompson, 2006.

DAVIS, Mike. Planeta Favela. São Paulo: Boitempo, 2006.

ELIAS, Norbert.; SCOTSON, John L. Os Estabelecidos e os Outsiders: sociologia das relações de poder em uma pequena comunidade. Rio de Janeiro: Zahar, 2000.

FERNANDES, Florestan. A integração do negro na sociedade de classes: no limiar de uma nova era. v.2. São Paulo:Globo, 2008.

PINTO, Costa. 0 negro no Rio de Janeiro: relações de raça numa sociedade em mudança. 2.ed. Rio de Janeiro: UFRJ, 1998.

RABENHORST, Eduardo. A dignidade do homem e os perigos da pós-humanidade. Verba Juris. João Pessoa, v. 4, n. 4, pp. 105-126, jan./dez., 2005.

RODRIGUES FILHO, Mario. O Negro no Futebol Brasileiro. Rio de Janeiro: Mauad, 2003.
WACQUANT, Loïc. Putas, escravos e garanhões: linguagens de exploração e de acomodação entre boxeadores profissionais. Mana - Estudos de Antropologia Social. Rio de Janeiro, v. 6, n. 2, p. 127-146, 2000.

WACQUANT, Loïc. Corpo e alma: notas etnográficas de um aprendiz de boxe. Rio de Janeiro: Relume Dumará, 2002.

WACQUANT, Loïc. Punir os pobres: a nova gestão da miséria nos Estados Unidos. 2. ed. Rio de Janeiro: Revan, 2003.

WACQUANT, Loïc. A aberração carcerária à moda francesa. Dados - Revista de Ciências Sociais. Rio de Janeiro, v. 47, n. 2, p. 215-232, 2004.

ZAFFARONI, Raúl. Em busca das penas perdidas. 5.ed. Rio de Janeiro: Revan, 2001.

ZAFFARONI, Raúl.; LEMGRUBER, Julita. A Esquerda Tem Medo, Não Tem Política de Segurança Pública.

Revista Brasileira de Segurança Pública. sine locus, v. 1, n. 1, pp. 130-139, 2007. 